\title{
The effect of adenoid tissue volume on mean platelet volume and neutrophil-to-lymphocyte ratio
}

\author{
Yakup Yegin $^{1}$, Mustafa Çelik ${ }^{* 1}$, Ahmet Altıntaş ${ }^{2}$ Burak Olgun$^{1}$, Baver Maşallah Şimşek ${ }^{1}$ and Fatma Tülin Kayhan ${ }^{1}$ \\ ${ }^{1}$ Bakırköy Dr.Sadi Konuk Training and Research Hospital, Department of Otorhinolaryngology - Head and Neck Surgery, Istanbul, Turkey \\ ${ }^{2}$ Fatih Medicalpark Private Hospital, Department of Otorhinolaryngology - Head and Neck Surgery, Istanbul, Turkey
}

\begin{abstract}
Objectives: To explore the relationships between mean platelet volume (MPV), neutrophil to lymphocyte ratio (NLR) and the size of adenoid hypertrophy(AH) and the effect of adenoidectomy on MPV levels and NLR values.

Subjects and methods: In total, 132 ( 66 males, 66 females; average age $7.10 \pm 3.62$ years; range, $3-18$ years) children who underwent adenoidectomy were included in the study. The patients were divided into two groups according to the size of adenoid tissue volume. Group A was consist of 72 patients with grade $3 \mathrm{AH}$, while group B was consist of 60 patients with grade 4 AH. Preoperative MPV levels and NLR values of group A and B were compared with measurements in the postoperative third month. A p-value $<0.05$ was considered to reflect statistical significance.

Results: In group A, mean preoperative MPV values were $7.80 \pm 1.14 \mathrm{fL}$ and mean postoperative MPV values were $8.06 \pm 1.02 \mathrm{fL}$, respectively. In group B, mean preoperative MPV values were $7.44 \pm 1.86 \mathrm{fL}$ and mean postoperative MPV values were $7.68 \pm 1.14 \mathrm{fL}$, respectively. No statistically significant difference in mean MPV values was observed between pre- and postoperatively in both groups $A$ and $B(p=0.190, p=0.259$, respectively). In group A, the preoperative values of NLR were $1.62 \pm 1.10$ and the postoperative values of NLR were $1.34 \pm 2.86$, respectively. In group B, the preoperative values of NLR were $1.38 \pm 0.92$ and the postoperative values of NLR were $1.40 \pm 1.12$, respectively. No statistically significant difference in mean NLR values was observed between pre- and postoperatively in both groups $\mathrm{A}$ and $\mathrm{B}(\mathrm{p}=0.137, \mathrm{p}=0.191$, respectively).
\end{abstract}

Conclusion: Adenoidectomy did not decrease MPV levels and NLR values in patients with grade 3 and $4 \mathrm{AH}$. Future randomized studies should explore the relationship between the MPV levels, NLR values and all of the size of AH in larger numbers of patients.

\section{Introduction}

Adenoid hypertrophy(AH) was first described by Wilhelm Meyer in 1868 , is the most common cause of upper airway obstruction in childhood [1]. AH can cause symptoms such as mouth breathing, nasal congestion, hyponasal speech, snoring, and obstructive sleep apnea (OSA), as well as chronic sinusitis and recurrent otitis media. More serious long-term sequelae, typically secondary to OSA, include cardiovascular morbidity such as decreased right ventricular ejection fraction, left ventricular hypertrophy, elevated diastolic blood pressure [2]. Therefore, cardiovascular morbidity is closely associated with the functions of the platelets [3].

Mean platelet volume(MPV) is considered to be a parameter used as an index of platelet functions. Larger platelets are more reactive than platelets of normal ones. Also, MPV is considered as a predictive value of aterosclerosis [4]. In literature, increasing MPV levels have been associated with the prognosis of some diseases including such as hypertension, unstable angina pectoralis and OSA [5,6]. The study of Sagit et al. [7] have shown that MPV levels are elevated in patients with marked septal deviation. They explained that the elevated in MPV levels of the patients with marked nasal septal deviation could be prevented by septoplasty. The study of Varol et al. [4] have reported that MPV levels were increased in patients with severe OSA.

Neutrophil to lymphocyte ratio(NLR) is proposed as an index of systemic inflammation [8]. NLR can be easily determined by a simple complete blood count analysis and is a valuable index paramater in diseases such as sudden hearing loss, certain some cancers, autoimmune and cardiovascular diseases $[9,10]$. Neutrophils are essential for cytokine production in acute process in inflammatory disorders while lymphocyte are important for cytokine production in chronic process in inflammatory disorders. Also, adenoid tissues have an important role in the production of immunoglobulins and the development of lymphocytes [11].

To our knowledge, there is no reported study that exploring the relationships between MPV, NLR and the size of AH. We address this topic in the present study. We explored the relationships between MPV, NLR and the size of AH and the effect of adenoidectomy on MPV levels and NLR values.

\section{Materials and methods}

We retrospectively reviewed data collected from January 2012 to September 2015 on patients treated in the Department of

Correspondence to: Dr. Mustafa ÇELIK, Bakırköy Dr. Sadi Konuk Eğitim ve Araştırma Hastanesi, Zuhuratbaba Mah. Tevfik Sağlam Cad. No:11, Bakırköy, Istanbul, Türkiye, Tel: 090 (212) 4147282; E-mail: dr.mcelik@yahoo.com

Key words: adenoid hypertrophy, mean platelet volume, neutrophil to lymphocyte ratio, adenoidectomy

Received: January 07, 2017; Accepted: January 27, 2017; Published: January 30 2017 
Otolaryngology, Head-and-Neck Surgery, of our hospital. In total, 132 children who underwent adenoidectomy were included in the study. Patients with previous history of adenoidectomy, genetic syndromes, congenital malformations, cleft palate, nasal septal deviation, sinonasal infection, chronic diseases, and hematological diseases were excluded from the study. All parents of the patients were informed about the study and a written consent was obtained from each parents of the patients. The study protocol was approved by the institutional Ethics Committee. The study was conducted in accordance with the principles of Helsinki Declaration. All of the patients presented with nasal congestion. All of the patients were followed up at least six months prior to surgery in our clinic. All the patients had endoscopic examination of the nose and postnasal space, pneumatic otoscopy and tympanometry preoperatively. The preoperative tympanograms were normal (type A) in all patients. The tympanic membranes were mobile in all patients by using pneumatic otoscopy. Adenoid volume was classified as follows; grade 1, adenoid tissue completes less than $25 \%$ of choana; grade 2 , adenoid tissue completes $25-50 \%$ of choana; grade 3 , adenoid tissue completes $50-75 \%$ of choana and grade 4 , adenoid tissue completes $75-100 \%$ of choana. All patients had grade 3 and 4 $\mathrm{AH}$ with at least 3 months trail of medical treatment. The patients included in the study were divided into two groups according to the size of adenoid tissue volume. Group A was consist of 72 patients with grade $3 \mathrm{AH}$, while group $\mathrm{B}$ was consist of 60 patients with grade $4 \mathrm{AH}$. All operations risks and complications were explained to children's parents. Adenoidectomy was performed by using St.Clair-Thomsen ${ }^{\circ}$ curate under general anesthesia in supine position and heamostases was secured by packing. All the operations were performed by one of the surgeons in our department. All chidren were clinically no symptoms of infection at the time of adenoidectomy. Routine preoperative blood samples were taken from the antecubital vein into tubes with ethylenediamine-tetracetic acid(EDTA) by a nurse. Neutrophil, lymphocyte and MPV were measured by hematology analyzer machine. Normal values for MPV were accepted as 6.0-11.0 fl. NLR was calculated from the differential count by dividing the neutrophil measurement by the lymphocyte measurement. All of the patients were invited for control examinations at post-operative first week and third month. All of the patients had no adenoid tissue at choana using by transnasal flexible endoscopy in the postoperative third month. Blood samples were taken again in the postoperative third month, and the measurements were compared with preoperative measurements.

\section{Statistical analysis}

Number Cruncher Statistical System (NCSS) 2007 software (Kaysville, UT, USA) was used for all statistical analyses. Descriptive statistics (means and standard deviation, medians with interquartile range) were derived. The significance of intergroup differences was analyzed using Student's $t$-test, and the significance of the medians was analyzed with the Mann-Whitney U-test. A paired $t$-test was performed to test differences between preoperative and postoperative values of MPV and NLR. Intragroup data comparisons were performed using the Wilcoxon's signed rank test. A $p$-value $<0.05$ was considered to reflect statistical significance.

\section{Results}

We included 132 patients: 66 (50.0\%) females and 66 (50.0\%) males. Their average age was $7.10 \pm 3.62$ years (range: $3-18$ years). There were 72 patients in group $A$ and 60 in group $B$. The age and gender were not significantly different between the groups $(\mathrm{p}=0.806)$. In group $\mathrm{A}$, mean preoperative MPV values were $7.80 \pm 1.14 \mathrm{fL}$ and mean postoperative
MPV values were $8.06 \pm 1.02 \mathrm{fL}$, respectively. No statistically significant difference in mean MPV values was observed between pre- and postoperatively in group $\mathrm{A}(\mathrm{p}=0.190)$. In group $\mathrm{B}$, mean preoperative MPV values were $7.44 \pm 1.86 \mathrm{fL}$ and mean postoperative MPV values were $7.68 \pm 1.14 \mathrm{fL}$, respectively. No statistically significant difference in mean MPV values was observed between pre- and postoperatively in group $B(p=0.259)$ (Table 1$)$. In group $A$, the preoperative values of NLR were $1.62 \pm 1.10$ and the postoperative values of NLR were $1.34 \pm 2.86$, respectively. No statistically significant difference in mean NLR values was observed between pre- and postoperatively in group A $(p=0.137)$. In group $B$, the preoperative values of NLR were $1.38 \pm$ 0.92 and the postoperative values of NLR were $1.40 \pm 1.12$, respectively. No statistically significant difference in mean NLR values was observed between pre- and postoperatively in group $\mathrm{B}(\mathrm{p}=0.191)$ (Table 2).

\section{Discussion}

In literature, there have been few studies of exploring the relationship between MPV and AH [12]. MPV levels show indirectly the cardiopulmonary risks and morbidity. Patients with elevated MPV levels seem to have bad prognoses in unstable angina pectoris, myocardial infarction and stroke [2-4]. In literature, previous studies explored the effect of adenoidectomy on MPV levels. The study of Kucur et al. [12] have reported that MPV levels were significiantly higher in patients with $\mathrm{AH}$ than in healthy controls and were significiantly lower in patients with AH after adenoidectomy. They suggested that MPV, a determinant of platelet activation, was elevated in patients with $\mathrm{AH}$ and adenoidectomy was an effective therapeutic measure in such patients. Increased platalet activation may be related to an increase of cardiopulmonary risk in patients with AH. The study of Soyalıç et al. [13] have reported that MPV was higher in children with adenotonsillar hypertrophy and that adenotonsillectomy lowers MPV levels in such patients. In contrast, the study of Cengiz et al. [14] have evaluated the associations between MPV levels and chronic tonsillitis-AH in children. They classified children into three groups. Group 1 consisted of patients who underwent adenoidectomy, whereas group 2 consisted of patients who underwent adenotonsillectomy and, group 3 consisted of healthy patients as control groups. MPV values in groups 1,2 and 3 were $6.6 \pm 0.8,6.6 \pm 0.7$ and $7.3 \pm 0.9$, respectively, in their study. Also, they reported that MPV values in groups 1 and 2 were significiantly lower than control group and there was no significiant difference between group 1 and 2. These studies lead to new discussions. In the present study, the patients were divided into

Table 1. Mean platelet volume in the two groups.
\begin{tabular}{|l|c|c|c|}
\hline MPV & $\begin{array}{c}\text { Preoperative MPV } \\
\text { levels }\end{array}$ & $\begin{array}{c}\text { Postoperative MPV } \\
\text { levels }\end{array}$ & ${ }^{a} \boldsymbol{p}$ \\
\hline Group A & $7.80 \pm 1.14$ & $8.06 \pm 1.02$ & $0.190^{*}$ \\
\hline Group B & $7.44 \pm 1.86$ & $7.68 \pm 1.14$ & $0.259^{*}$ \\
\hline${ }^{b} p$ & $0.968^{*}$ & $0.642^{*}$ & \\
\hline
\end{tabular}

Abbreviations: $M P V$, mean platelet volume.

${ }^{a} \boldsymbol{p}$ : Paired Samples $t$-test $\quad{ }^{b} \boldsymbol{p}$ : Mann-Whitney U-test.

${ }^{*} p<0.05$

Table 1. Mean platelet volume in the two groups.

\begin{tabular}{|l|c|c|c|}
\hline NLR & $\begin{array}{c}\text { Preoperative NLR } \\
\text { levels }\end{array}$ & $\begin{array}{c}\text { Postoperative NLR } \\
\text { levels }\end{array}$ & ${ }^{a} \boldsymbol{p}$ \\
\hline Group A & $1.62 \pm 1.10$ & $1.34 \pm 2.86$ & $0.137^{*}$ \\
\hline Group B & $1.38 \pm 0.92$ & $1.40 \pm 1.12$ & $0.191^{*}$ \\
\hline${ }^{b} p$ & $0.768^{*}$ & $0.812^{*}$ & \\
\hline
\end{tabular}

Abbreviations; NLR, neutrophil-to-lymphocyte ratio.

${ }^{a} p$ : Paired Samples $t$-test ${ }^{b} \boldsymbol{p}$ : Mann-Whitney U-test.

${ }^{*} p<0.05$ 
two groups according to the size of adenoid tissue volume. Group A was consist of 72 patients with grade $3 \mathrm{AH}$, while group $\mathrm{B}$ was consist of 60 patients with grade $4 \mathrm{AH}$. In group $\mathrm{A}$, mean preoperative MPV values were $7.80 \pm 1.14 \mathrm{fL}$ and mean postoperative MPV values were $8.06 \pm 1.02 \mathrm{fL}$, respectively. In group B, mean preoperative MPV values were $7.44 \pm 1.86 \mathrm{fL}$ and mean postoperative MPV values were 7.68 $\pm 1.14 \mathrm{fL}$, respectively. No statistically significant difference in mean MPV values was observed between pre- and postoperatively in both groups A and B. To our knowledge, there is no reported study that exploring the relationships between MPV and the size of AH. The present study provides the first report of explored the relationships between MPV and the size of AH. Therefore, we cannot assert that adenoidectomy may reduce cardiovascular morbidity considering the lack of assessment of long-term outcomes. Confounding variables that were addressed include the study design, the study size, the characteristics of patients, and the size of $\mathrm{AH}$. To our knowledge, there is no reported study that focused on the effect of duration of $\mathrm{AH}$ on MPV levels in patients with AH. However, determination of the effect of duration of AH on MPV levels is objectively difficult. NLR is considered as an potential marker in identification of the disease severity in inflammatory disorders, including such as cardiovascular diseases, sudden hearing loss, vestibular neuronitis, autoimmune diseases $[9,10]$. The adenoid tissues, like all lymphoid tissue, enlarge when infected. Although lymphoid tissue does act to fight infection, sometimes bacteria and viruses can lodge within it and survive. Chronic infection, either viral or bacterial, can keep the pad of adenoid tissues enlarged for years, even into adulthood [11]. To our knowledge, there is no reported study that exploring the relationships between NLR and the size of AH. In group A, the preoperative values of NLR were $1.62 \pm 1.10$ and the postoperative values of NLR were $1.34 \pm 2.86$, respectively. In group B, the preoperative values of NLR were $1.38 \pm$ 0.92 and the postoperative values of NLR were $1.40 \pm 1.12$, respectively. No statistically significant difference in mean NLR values was observed between pre- and postoperatively in both groups A and B. The present study provides the first report of explored the relationships between NLR and the size of AH.

Limitations of this study included a retrospective study design, the sample size, the lack of randomization and the lack of assessment of the relationships between MPV levels and NLR values in patients with grade 1 and $2 \mathrm{AH}$. Only patients with grade 3 and $4 \mathrm{AH}$ were included. If the study design was randomized study with patients with all of the size of $\mathrm{AH}$, the study may be more valuable. Future randomized studies should explore the relationship between the MPV levels, NLR values and all of the size of AH in larger numbers of patients.

\section{Conclusion}

In conclusion, we observed no statistically significant difference in mean MPV levels and NLR values between pre-and postoperatively in both groups A and B. Adenoidectomy did not decrease MPV levels and NLR values in patients with grade 3 and $4 \mathrm{AH}$. Future randomized studies should explore the relationship between the MPV levels, NLR values and all of the size of $\mathrm{AH}$ in larger numbers of patients.

\section{References}

1. Chohan A, Lal A, Chohan K, Chakravarti A, Gomber S (2015) Systematic review and meta-analysis of randomized controlled trials on the role of mometasone in adenoid hypertrophy in children. Int J Pediatr Otorhinolaryngol. 79:1599-1608. [Crossref]

2. Izu SC, Itamoto CH, Pradella-Hallinan M, Pizarro GU, Tufik S, et al. (2010) Obstructive sleep apnea syndrome (OSAS) in mouth breathing children. Braz J Otorhinolaryngol 76: 552-556.[Crossref]

3. Park Y, Schoene N, Harris W (2002) Mean platelet volume as an indicator of platelet activation: methodological issues. Platelets 13: 301-306. [Crossref]

4. Varol E, Ozturk O, Gonca T, Has M, Ozaydin M, et al. (2010) Mean platelet volume is increased in patients with severe obstructive sleep apnea. Scand J Clin Lab Invest 70 : 497-502.[Crossref]

5. Vizioli L, Muscari S, Muscari A (2009) The relationship of mean platelet volume with the risk and prognosis of cardiovascular diseases. Int J ClinPract 63: 1509-1515. [Crossref]

6. Greisenegger S, Endler G, Hsieh K, Tentschert S, Mannhalter C, Lalouschek W (2004) Is elevated mean platelet volume associated with a worse outcome in patients with acute ischemic cerebrovascular events?. Stroke 35: 1688-1691. [Crossref]

7. Sagit M, Korkmaz F, Kavugudurmaz M, Somdas MA (2012) Impact of septoplasty on mean platelet volume levels in patients with marked nasal septal deviation. J Craniofac Surg 23: 974-976.[Crossref]

8. Bhat T, Teli S, Rijal J, Bhat H, Raza M, et al. (2013) Neutrophil to lymphocyte ratio and cardiovascular diseases: a review. Expert Rev Cardiovasc Ther 11: 55-59.[Crossref]

9. Tamhane UU, Aneja S, Montgomery D, Rogers EK, Eagle KA, et al. (2008) Association between admission neutrophil to lymphocyte ratio and outcomes in patients with acute coronary syndrome. Am J Cardiol 102: 653-657. [Crossref]

10. O'Brien CE, Price ET (2013) The blood neutrophil to lymphocyte ratio correlates with clinical status in children with cystic fibrosis: a retrospective study. PLoS One 8: e77420.[Crossref]

11. Shin SY, Choi SJ, Hur GY, Lee KH, Kim SW, et al. (2009) Local production of total IgE and specific antibodies to the house dust mite in adenoid tissue. Pediatr Allergy Immunol. 20:134-141. [Crossref]

12. Kucur C, Kulekci S, Zorlu A, Savran B, Oghan F, et al. (2014) Mean platelet volume levels in children with adenoid hypertrophy. J Craniofac Surg 25: e29-31.[Crossref]

13. Soyaliç H, Somuk BT, Dogru S, Gürbüzler L, Göktas G, et al. (2015) Evaluation of mean platelet volume and its ratio over platelet count in children with obstructive sleep apnea syndrome. Kulak Burun BogazIhtis Derg 25: 16-21. [Crossref]

14. Cengiz C, Erhan Y, Murat T, Ercan A, Ibrahim S, et al. (2013) Values of mean platelet volume in patients with chronic tonsillitis and adenoid hypertrophy. Pak J Med Sci 29 569-572.[Crossref]

Copyright: (C2017 Yegin Y. This is an open-access article distributed under the terms of the Creative Commons Attribution License, which permits unrestricted use, distribution, and reproduction in any medium, provided the original author and source are credited. 